\title{
CHARLES BAUDELAIRE: FRANCISCAE MEAE LAUDES
}

\section{PREVEDEL PRIMOŽ SIMONITI}

FRANCISCAE MEAE LAUDES

(Les Fleurs du Mal LX)

Vers composés pour une modiste érudite et dévote

Novis te cantabo chordis, o novelletum quod ludis

In solitudine cordis.

Esto sertis implicata, O femina delicata

Per quam solvuntur peccata!

Sicut beneficum Lethe,

Hauriam oscula de te,

Quae imbuta es magnete.

Quum vitiorum tempestas

Turbabat omnes semitas,

Apparuisti, Deitas,

Velut stella salutaris

In naufragiis amaris ...

- Suspendam cor tuis aris!

Piscina plena virtutis,

Fons aeternae juventutis

Labris vocem redde mutis!

Quod erat spurcum, cremasti;

Quod rudius, exaequasti;
HVALNICA MOJE FRANÇOISE

(Rože Zla LX)

Verzi, zloženi za neko izobraženo in pobožno modistko

$\mathrm{Z}$ novih strun ti pel bom hvalo, o dekletce, ki igravo boš srcá samoto ugnalo.

$\mathrm{V}$ vence bodi mi ovita, o ti ženska čudovita, s tabo je pregreha izmita!

Pil kot dobrodejna Lete bom poljub tvoj, ki prežeta si s privlačnostjo magneta.

Ko je vihra grehov vstala in vsa pota zavozlala, si se, boštvo, prikazala,

rešnja zvezda mi čolnarju $\mathrm{v}$ brodolomu in viharju ...

- Dar srce bo na oltarju!

Ti zbiralnik, poln kreposti, vrelec večne si mladosti, nemih ust spet glas dopusti!

Prej nečisto upepelila, prej robato si zgladila, 
Quod debile, confirmasti.

In fame mea taberna,

In nocte mea lucerna,

Recte me semper guberna.

Adde nunc vires viribus,

Dulce balneum suavibus

Unguentatum odoribus!

Meos circa lumbos mica,

O castitatis lorica,

Aqua tincta seraphica;

Patera gemmis corusca,

Panis salsus, mollis esca,

Divinum vinum, Francisca! prej slabotno okrepila.

Krčma lačnemu mi bodi, v moji noči luč povsodi, zmeraj k pravemu me vodi!

Zdaj močem moči dodajaj, sladka kopel, in opajaj $\mathrm{z}$ vonjem olj, mazil in slaja.

Ledja mi iskreč se oklêni, čistosti oklep zglajeni, z vodo sêrafsko škropljeni!

Kupe lesk $\mathrm{z}$ biserovino, kruh s soljo in hrano fino, Françoise, božansko vino! 